\title{
MODEL OPTIMASI BEBAN MENGAJAR DOSEN DENGAN MEMINIMUMKAN DEVIASI RATA-RATA BEBAN MENGAJAR
}

\author{
Imam Ekowicaksono ${ }^{1 *}$, I Wayan Wiprayoga Wisesa ${ }^{2)}$ \\ ${ }^{1}$ Teknik Informatika, Institut Teknologi Sumatera \\ Email: imam.wicaksono@if.itera.ac.id \\ ${ }^{2}$ Teknik Informatika, Institut Teknologi Sumatera \\ Email: wayan.wisesa@if.itera.ac.id
}

\begin{abstract}
At the beginning of each semester, the faculty member will determine the teaching load for each lecturer. Teaching load assigned for each lecturer is carried out by considering the lecturers' courses and scientific groups. In addition, the assignment method for teaching load consider the balance of the average teaching load. This study investigate the teaching load assignment problem considering the balance of the teaching load for each lecturer. The linear programming model is used to model the teaching load of lecturers. This teaching load model was applied at the Informatics Program, Institut Teknologi Sumatera for the even semester. The model yields a minimum total deviation of the average teaching load of lecturers is 8.05 credits, calculated using the branch and bound algorithm with 7,258,538 iterations.
\end{abstract}

Keywords: Teaching assignment, Branch and bound, Linear programming.

\begin{abstract}
ABSTRAK
Setiap awal semester, setiap program studi akan menentukan beban mengajar setiap dosen. Perhitungan beban mengajar setiap dosen dilakukan dengan mempertimbangkan mata kuliah dan kelompok keilmuan dosen tersebut. Selain itu, perhitungan beban mengajar dosen akan mempertimbangkan keseragaman rata-rata beban mengajar dosen. Penelitian ini bertujuan memodelkan secara matematis beban mengajar dosen dengan memperhatikan keseragaman beban mengajar setiap dosen. Model pemrograman linear digunakan untuk memodelkan beban mengajar dosen. Model beban mengajar ini diaplikasikan di Program Studi Teknik Informatika, Institut Teknologi Sumatera untuk semester genap. Hasil yang diperoleh, deviasi minimum total rata-rata beban mengajar dosen adalah 8.05 SKS yang dikalkulasikan menggunakan algoritma branch and bound dengan 7.258 .538 iterasi.
\end{abstract}

Kata kunci: Beban mengajar dosen, branch and bound, linear programming

\section{PENDAHULUAN}

Penentuan beban mengajar dosen merupakan hal yang selalu dilakukan oleh program studi di kampus-kampus di Indonesia. Dalam pelaksanaannya, perhitungan beban mengajar dosen masih dilakukan secara manual berdasarkan bidang minat dan 
keilmuan dosen terhadap mata kuliah tertentu. Perhitungan beban mengajar dosen dilakukan dengan memerhatikan beban mengajar maksimum yang dapat diampu oleh seorang dosen. Menurut Dirjen Dikti (2010), beban mengajar maksimum yang dapat diampu oleh seorang dosen ditambah dengan kegiatan penelitian adalah 16 SKS.

Masalah penentuan beban mengajar dosen ini dapat dipandang sebagai suatu permasalahan penjadwalan, dimana terdapat dua entitas, yaitu dosen dan mata kuliah, yang akan dipasangkan sesuai dengan bidang keahliannya. Masalah pemasangan dosen dengan mata kuliah dapat dipandang sebagai permasalahan kombinasi dari dosen dengan mata kuliah. Permasalahan kombinasi tersebut dapat dimodelkan kedalam bentuk pemrograman linear (mahmudy, 2006). Model pemrograman linear terdiri dari 3 (tiga) komponen dasar, yaitu variabel keputusan, fungsi obyektif (tujuan) dan kendala.

Pada penelitian sebelumnya, fungsi obyektif yang digunakan adalah memaksimumkan total biaya (tingkat kesukaan dosen terhadap mata kuliah tertentu) (Mahmudy, 2006), kesesuaian keminatan mayor dan minor dosen dengan mata kuliah (Nopianti, 2019), kesesuaian kompetensi dan kemerataan pembagian tugas mengajar antara satu dosen dengan dosen yang lain (Janah, 2016) serta meminimumkan tingkat kesalahan dalam memasangkan dosen dengan mata kuliah yang sesuai dengan bidang peminatannya. Penelitian Mahmudy (2006), Nopianty (2019), Dewanti (2018) dan Janah (2016) menggunakan algoritma genetika untuk menyelesaikan permasalahan penentuan beban mengajar dosen, sedangkan Abduh (2017) menggunakan algoritma particle swarm optimization (PSO) untuk menyelesaikan permasalahan optimasi beban mengajar dosen.

Pada penelitian ini, model optimasi beban mengajar dosen akan dibangun menggunakan model pemrograman linear dengan fungsi obyektif meminimumkan deviasi rata-rata beban mengajar antar dosen. Fungsi obyektif ini akan dimodelkan dengan teknik linear programming.

\section{METODOLOGI}

\subsection{Model Penugasan}

Masalah penugasan merupakan kasus spesial dari masalah transportasi dimana penentu keputusan menginginkan untuk menugaskan sejumlah pekerjaan kepada sejumlah pekerja secara satu per satu, sehingga tidak ada pekerja yang mendapatkan lebih dari 1 pekerjaan dan setiap pekerjaan hanya dikerjakan tidak lebih dari seorang pekerja. Total biaya untuk mengerjakan seluruh pekerjaan kepada setiap pekerja harus diminimumkan. Masalah penugasan dapat direpresentasikan sama dengan masalah transportasi dengan mengasumsikan bahwa (Sarker, 2008):
a. Setiap pekerjaan adalah titik asal
b. Setiap pekerja adalah titik tujuan
c. Terdapat tepat satu penawaran untuk setiap titik asal
d. Terdapat tepat satu permintaan untuk setiap titik tujuan
e. Biaya transportasi sama dengan biaya penugasan 


\subsection{Linear Programming}

Masalah pemrograman linear adalah sebuah permasalahan optimasi yang memenuhi kriteria berikut (Winston, 2004):

a. Bertujuan untuk memaksimumkan (atau meminimumkan) sebuah fungsi linear dari variabel keputusan. Fungsi ini disebut sebagai fungsi obyektif (objective function).

b. Nilai variabel keputusan harus memenuhi kendala-kendala tertentu. Setiap kendala harus berupa persamaan atau pertidaksamaan linear.

c. Pembatas tanda diinisialisasikan ke setiap variabel keputusan. Untuk setiap variabel keputusan $\mathrm{x}_{\mathrm{ij}}$, pembatas tanda mensyaratkan bahwa $\mathrm{x}_{\mathrm{ij}}$ harus berupa tak negatif $\left(\mathrm{x}_{\mathrm{ij}} \geq\right.$ 0 ) atau tidak ada batasan tanda.

\section{HASIL DAN PEMBAHASAN}

\subsection{Model Persamaan linear}

Beban mengajar dosen merupakan masalah yang dapat dimodelkan ke dalam bentuk pemrograman linear. Permasalahan ini bertujuan untuk mencari pasangan dosen yang akan mengajar mata kuliah tertentu yang memaksimumkan kapabilitas dosen dalam mengajar mata kuliah tersebut. Selain itu, model akan meminimumkan deviasi beban mengajar antar dosen.

\subsubsection{Parameter dan Variabel Model}

Penelitian ini menggunakan beberapa himpunan untuk menggambarkan entitas yang digunakan. Entitas dosen dilambangkan dengan himpunan $\mathbf{L}$, entitas mata kuliah dilambangkan dengan $\mathbf{S}$ dan entitas kelas dilambangkan dengan $\mathbf{C}$. Selain himpunan, terdapat beberapa parameter yang digunakan dalam penelitian. Parameter $p$ dan $q$ merupakan parameter yang merepresentasikan beban mengajar minimum dan maksimum yang dapat diampu oleh seorang dosen. $r$ adalah banyaknya dosen yang dapat mengajar pada satu mata kuliah di kelas-kelas pararel, sedangkan $u$ adalah parameter yang menyatakan maksumum jumlah mata kuliah yang dapat diajarkan oleh seorang dosen. Parameter $v$ menggambarkan jumlah maksimum kelas pararel yang dapat diampu oleh seorang dosen di mata kuliah yang sama. $S K S_{j}$ merupakan beban SKS pada mata kuliah $j$.

Variabel yang digunakan dalam penelitian adalah $x_{i j k}, y_{i j k}$ dan $s t_{i}$. Variabel $x_{i j k}, y_{i j}$ dan $s t_{i}$ adalah variabel yang bernilai biner.

$x_{i j k}=\left\{\begin{array}{l}1, \quad \text { jika dosen } i \text { mengajar mata kuliah } j \text { di kelas } k \\ 0, \quad \text { lainnya }\end{array} ; \forall i \in \mathbf{L}, j \in \mathbf{S}, k \in \mathbf{C}\right.$,

$y_{i j}=\left\{\begin{array}{ll}1, & \text { jika dosen } i \text { mengajar mata kuliah } j \\ 0, & \text { lainnya }\end{array} \quad \forall i \in \mathbf{L}, j \in \mathbf{S}\right.$, 
$s t_{i}= \begin{cases}1, & \text { jika dosen } i \text { aktif mengajar } ; \quad \forall i \in \mathbf{L}, \\ 0, & \text { lainnya }\end{cases}$

$d_{i}^{+}$adalah variabel total SKS deviasi untuk beban mengajar dosen yang lebih besar dari ratarata beban mengajar seluruh dosen,

$d_{i}^{-}$adalah variabel total SKS deviasi untuk beban mengajar dosen yang lebih kecil dari ratarata beban mengajar seluruh dosen.

\subsubsection{Fungsi Obyektif}

Model optimasi beban mengajar dosen memunyai fungsi objektif untuk memininmumkan deviasi beban mengajar antar dosen.

$$
\operatorname{Max} z=\sum_{i=1}^{l}\left(d_{i}^{+}+d_{i}^{-}\right)
$$

Model optimasi ini memiliki kendala sebagai berikut:

1. Variabel beban SKS yang dibebankan kepada dosen $i\left(b_{i}\right)$ dihitung dengan jumlah SKS yang dibebankan kepada dosen tersebut.

$$
\sum_{i=1}^{l} x_{i j k} \times \mathrm{st}_{i} \times \mathrm{SKS}_{\mathrm{j}}=\mathrm{b}_{\mathrm{i}}, \quad \forall j \in \mathbf{S}, k \in \mathbf{C}
$$

2. Rata-rata SKS beban mengajar dosen $(\bar{b})$ ditentukan dangan menjumlahkan semua beban dosen dibagi dengan jumlah dosen.

$$
\sum_{i=1}^{l} x_{i j k} \times \mathrm{st}_{i} \times \mathrm{SKS}_{\mathrm{j}}=\mathrm{b}_{\mathrm{i}} \times \bar{b}, \quad \forall j \in \mathbf{S}, k \in \mathbf{C}
$$

3. Selisih total beban SKS setiap dosen dengan rata-rata beban SKS dosen.

$$
b_{i}-\bar{b}-d_{i}^{+}+d_{i}^{-}=0, \quad \forall \mathrm{i} \in \mathbf{L}
$$

4. Setiap mata kuliah $j$ di kelas $k$ diajar oleh 1 orang dosen.

$$
\sum_{i=1}^{l} x_{i j k} \leq 1, \quad \forall j \in \mathbf{S}, k \in \mathbf{C}
$$

5. Setiap dosen mengajar minimal $p$ SKS dan maksimal $q$ SKS.

$$
p \times s t_{i} \leq \sum_{j, k=1}^{s, c} x_{i j k} \times s t_{i} \leq q \times s t_{i}, \quad \forall i \in \mathbf{L}
$$

6. Variabel keputusan $x_{i j k}$ dan $y_{i j}$ bernilai biner.

$$
x_{i j k}, y_{i j} \in\{0,1\}, \quad \forall i \in \mathbf{L}, j \in \mathbf{S}, k \in \mathbf{C}
$$


7. Variabel $d_{i}^{+}$dan $d_{i}^{-}$bernilai positif.

$$
d_{i}^{+}, d_{i}^{-} \geq 0 \quad \forall i \in \mathbf{L}
$$

\subsection{Studi Kasus}

Pada bagian studi kasus akan digunakan data penugasan mengajar pada Program Studi Teknik Informatika, Institut Teknologi Sumatera. Setiap dosen dipetakan kapabilitas mengajar mata kuliah tertentu sesuai dengan kelompok keahliannya. Jumlah dosen yang mengajar pada semester genap sebanyak 21 orang, dan jumlah mata kuliah yang dibuka di semester genap sebanyak 19 mata kuliah. Detail dosen dan mata kuliah beserta SKS dan banyaknya kelas pararel yang dibuka pada semester genap diberikan pada Tabel 1 dan Tabel 2.

\section{Tabel 1 Dosen aktif mengajar}

\begin{tabular}{ll}
\hline Dosen & Dosen \\
\hline RAY & MIR \\
RHA & AIC \\
RIK & MCT \\
AZR & ANS \\
ALR & MPS \\
HBF & MCU \\
IEW & OKT \\
IWW & AFO \\
HTA & IFA \\
AWJ & AAF \\
AIQ & \\
\hline
\end{tabular}

Tabel 2 Mata kuliah semester genap

\begin{tabular}{lcc}
\hline \multicolumn{1}{c}{ Mata Kuliah } & SKS & \# Kelas Pararel \\
\hline Algoritma dan Pemrograman II & 3 & 4 \\
Pemrograman Berorientasi Objek & 4 & 4 \\
Strategi Algoritma & 3 & 4 \\
Sistem Operasi & 3 & 4 \\
Basis Data & 3 & 4 \\
Dasar Rekayasa Perangkat Lunak & 2 & 4 \\
Probabilitas dan Statistika & 3 & 4 \\
Pengembangan Aplikasi Mobile & 3 & 4 \\
Proyek Perangkat Lunak & 4 & 4 \\
Kewirausahaan & 2 & 4 \\
Kapita Selekta Informatika & 3 & 4
\end{tabular}


Socio Informatika dan Etika Profesi

Keamanan Jaringan

Data Warehouse / Data Mining

Pervasive Computing

Visualisasi Data dan Informasi

Pemrograman Web Lanjut

Pengolahan Sinyal Digital

Information Retrieval (Perolehan Informasi)

$\begin{array}{ll}2 & 4 \\ 3 & 1 \\ 3 & 1 \\ 3 & 1 \\ 3 & 1 \\ 3 & 1 \\ 3 & 1 \\ 3 & 1\end{array}$

Dengan menggunakan algoritma branch and bound dengan 7258538 iterasi, didapatkan total deviasi minimum beban mengajar dosen sebesar 8.05 SKS. Sebaran beban mengajar dosen yang dihasilkan dapat dilihat pada Tabel 3.

Tabel 3 Hasil beban dan deviasi mengajar dosen

\begin{tabular}{lrrr}
\hline Dosen & Beban & \multicolumn{1}{c}{$\boldsymbol{d}_{\boldsymbol{i}}^{-}$} & \multicolumn{1}{c}{$\boldsymbol{d}_{\boldsymbol{i}}^{+}$} \\
\hline RAY & 9 & 0 & 0.95 \\
RHA & 8 & 0.05 & 0 \\
RIK & 9 & 0 & 0.95 \\
AZR & 6 & 2.05 & 0 \\
ALR & 8 & 0.05 & 0 \\
HBF & 8 & 0.05 & 0 \\
IEW & 6 & 2.05 & 0 \\
IWW & 8 & 0.05 & 0 \\
HTA & 6 & 2.05 & 0 \\
AWJ & 9 & 0 & 0.95 \\
AIQ & 6 & 2.05 & 0 \\
MIR & 9 & 0 & 0.95 \\
AIC & 9 & 0 & 0.95 \\
MCT & 8 & 0.05 & 0 \\
ANS & 8 & 0.05 & 0 \\
MPS & 9 & 0 & 0.95 \\
MCU & 9 & 0 & 0.95 \\
OKT & 6 & 2.05 & 0 \\
AFO & 8 & 0.05 & 0 \\
IFA & 6 & 2.05 & 0 \\
AAF & 6 & 2.05 & 0 \\
\hline & & &
\end{tabular}

Pada Tabel 3 dapat disimpulkan bahwa beban mengajar yang diampu setiap dosen hampir seragam dengan beban mengajar minimum sebanyak 6 SKS dan beban mengajar maksimum sebesar 9 SKS. Selisih antara beban mengajar minimum dan beban mengajar maksimum sebesar 3 SKS. Rata-rata beban mengajar dosen sebesar 7.67 SKS. Hal ini berarti selisih antara rata-rata beban mengajar dengan beban mengajar minimum dosen sebesar 1.67 
dan selisih rata-rata beban mengajar dengan beban mengajar maksimum dosen sebesar 1.33. Sebaran beban mengajar dosen secara visual dapat dilihat pada Gambar 1.

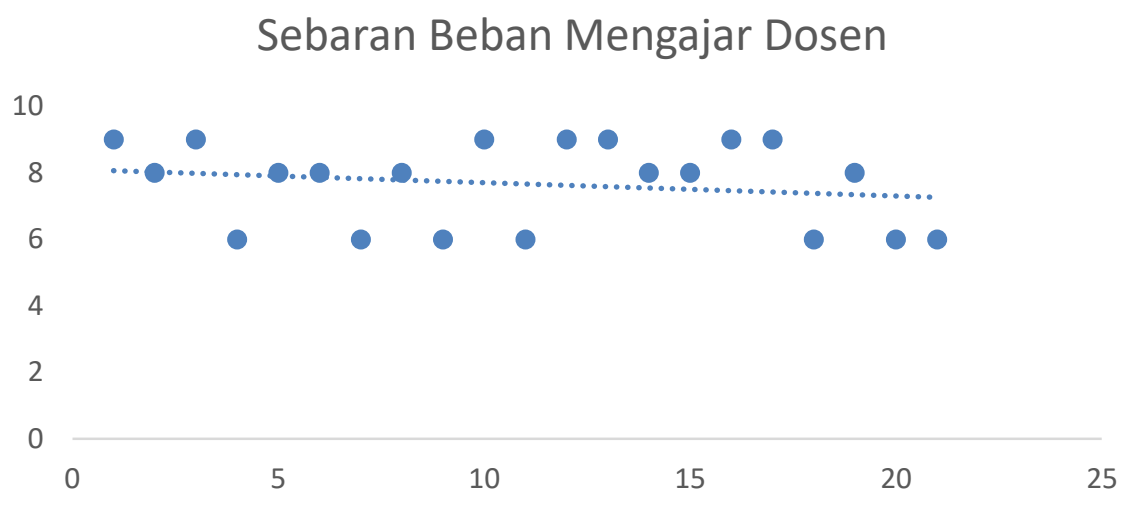

Gambar 1 Sebaran beban mengajar dosen

\section{SIMPULAN}

Berdasarkan hasil penelitian yang telah dilakukan, model optimasi beban mengajar dosen ini dapat menyelesaikan masalah penugasan beban mengajar dosen. Model optimasi ini menghasilkan solusi optimum menggunakan algoritma branch and bound. Solusi optimum yang didapat dari model optimasi beban mengajar dosen, dihasilkan dengan memasangkan dosen dengan kelas per mata kuliah yang menghasilkan kombinasi yang optimum.

\section{DAFTAR PUSTAKA}

Abduh, M; Regasari,R ; Putri, M; Muflikhah, L. 2017. Optimasi Pembagian Tugas Dosen Pengampu Mata Kuliah Dengan Metode Particle Swarm Optimization. Jurnal Pengembangan Teknologi Informasi dan Ilmu Komputer (J-PTIIK) Universitas Brawijaya, 1(10):989-999.

Dewanti, R; Novianingsih, K; Agustina, F. 2018. Penyelesaian Masalah Penugasan Dosen Pada Mata Kuliah Menggunakan Algoritma Genetika (Studi Kasus di Departemen Pendidikan Matematika Fpmipa Upi). Jurnal EurekaMatika, 6(1): 43-53.

Dikti, D. 2010. Pedoman beban kerja dosen dan evaluasi pelaksanaan tridharma perguruan tinggi.

Mahmudy, W.F. 2006. Penerapan algoritma genetika pada optimasi model penugasan. Natural, 10 No.3(January 2006):197-207.

Sarker, R. A. \& Newton, C. S., 2008. Optimization modelling : a practical introduction. In Cambridge university Press (Vol. 53, Issue 9). CRC Press. https://doi.org/10.1017/CBO9781107415324.004 


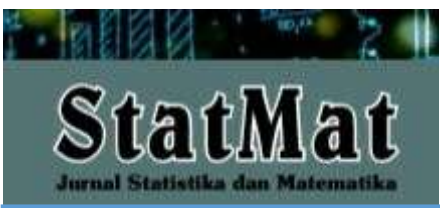

P-ISSN: 2655-3724 E-ISSN: 2720-9881

STATMAT (Jurnal Statistika dan Matematika), Vol. 2, No. 2, Juli 2020

Halaman: 115-122

@Prodi S-1 Matematika FMIPA Unpam

Winston, W.L; Goldberg, J.B. 2004. Operations research: applications and algorithms, volume 3. Thomson Brooks/Cole Belmont. 